\title{
Reclaiming the Girl Child From Self-Harm
}

\author{
Irene N. Mogbo", Felicia N. Modo, Christopher S. Uwah \\ Faculty of Education, University of Uyo, Uyo, P.M.B. 1017, Akwa Ibom State, Nigeria \\ *Corresponding author: Irenemogbo@yahoo.com(Irene N. Mogbo), Feliciamodo@uniuyo.edu.ng(Felicia N. Modo)
}

\begin{abstract}
There has been a marked increase in self-harm practices among youths, especially young girls. In the school system, scores of antisocial behaviours and academic maladjustment have been already observed. If left unchecked, deliberate self-harm may engender hideous problems in homes, schools and ultimately, the society. This paper examines the concept, forms, incidence and consequences of deliberate self-harm among young girls. The paper draws up viable measures that social workers may exploit in order to assist youths avoid deliberate self-harm practices by interfacing with families, schools and other social institutions.
\end{abstract}

Keywords Deliberate self-harm, Girl-Child, Counseling, Social Work

\section{Introduction}

Self-harm, also variously called self-injury, self-inflicted violence, self-injurious behaviour, and self-mutilation describes a range of behaviour that causes injury, intentionally, to oneself [1]. Most researchers opine that self-harm is an attention-seeking behaviour; nevertheless, this assumption is not always true. Many self-harmers are conscious of their injuries and scars and are often remorseful afterwards. Such shame and remorse often makes self-harmers hide their behaviour from others [2]. They may offer alternative explanations for their injuries, or conceal their scars with clothing [3, 4].

Noteworthy is the fact that remorseful self-harmers are not suicidal and as such their behaviour are usually not considered suicidal or para-suicidal. Generally, it is observed that most self-harmers never intend to end their own life. Some researchers opine that self-harmers simply use their behaviour as a coping mechanism against emotional pain or some discomfort or in an effort communicate inner turmoil $[5,6]$.

Other studies involving persons with developmental disabilities such as mental retardation have shown a strong correlation between such environmental factors as attention seeking and escape from social responsibilities and self-harm [7]. Also, it has been observed that some self-harmers suffer from dissociation, wanting to feel real or to fit into society's rules [8].

Most cases of self-harm involve cutting the skin with sharp objects [2, 9-10]. Nevertheless, self-harm methods employed depend largely on the self-harmer's inventiveness and determination to harm self. That is why cases of self-harm may involve such crude and brutal methods as burning, self-poisoning, embedding objects in the body, hair pulling, bruising, banging of one's head against a wall, drug abuse, abuse of substance, unsafe sexcapade, and disordered eating $[2,10]$. The body parts most preferred for self-injury are those areas that can be conveniently hidden from others [11]. Generally, it is believed that self-harm is not a disorder in itself, but a sign of an underlying disorder [4-5]. This explains why neither the DSM-IV-TR nor the ICD-10 documents any criteria for the diagnosis of self-harm.

Generally, youths live in an exciting time; an increasingly diverse and ever-changing society. Advances in information and communication technologies offer them the opportunity to learn behaviour patterns from all over the world via the electronic media. Youths therefore face varied developmental and academic challenges. To achieve healthy personal and social adjustment, youths - especially the girl child - needs supportive guidance and counselling.

In the school setting, there is an increased need for the provision of social work services, such as professional guidance and counselling by individual professionals and non-governmental agencies to help students avoid self-harm practices. It is commonly observed that students who self-harm also do poorly in their academics as a result of various psycho-academic deficits engendered by self-harm practices. Such deficits usually subsume frequent hospitalisation, truancy, attention deficits in classes, impaired memory, dissociative disorders, self-pity, and psychological withdrawal from academic engagements. These in turn variously lead to failing grades, school dropout and rustication (usually as a result of school staff mysticism and superstition).

\section{Materials and Methods}

This paper is a systematic review of literature on the causes and problems associated with self-harm. Relevant 
literature were obtained from libraries and resources centres in the study locale and the internet. Based on the emerging knowledge and the implications it holds for counsellors, the authors advance expert recommendations towards reclaiming the girl child from self-harm.

\section{Synthesis of Literature}

\section{Concept of Self-harm}

According to Powel [12], self-harm is a deliberate act to hurt oneself with drug or other materials in an attempt to cope with some difficult feelings challenges or situations that the person cannot share with other people. Self-harm can also be used as self defence mechanism to protect somebody's self-image from being damaged. In the later case, for instance a girl that has been known to be a brilliant girl came out in an examination with a lot of poor grades. This inconsistency in her grades becomes a mismatch with her former self concept of brilliance and good grades. Internally she will be sad and miserable. Her defence mechanism being unable to cope with the situation may lead her to examination anxiety and in extreme cases examination malpractices to defend her damaged self-concept.

Self-harm can also mean experiencing of low self-esteem, a state in which the girl feels that her ideas, opinions and emotions are not considered, important or valued by people in decision making matters. The girl child seeing herself in this light will not know internal peace in her mind. This internal lack of peace affects her whole being, leading to negative self-concept which affects her learning, work and even pregnancy negatively because her internal psychological environment is troubled and not peaceful. Externally this experience manifests itself as self-harm.

\section{General causes of self-harm}

Generally, mental illness, psychological factors, genetic factors, and substance misuse are found to be at the root of self-harm.

Mental illness: Persons with mental illness are more at risk of self-harm. This does not mean, however, that all who self-harm are mentally ill [3]. Such mental illnesses like autism spectrum disorders put sufferers at high risk of self-harm [13-14]. Other forms of mental illness that predispose individuals to self-harm include borderline personality disorder, bipolar disorder, depression, phobias, and conduct disorders [15-18]. Schizophrenia is also found to be associated with self-harm due, largely, to the fact that schizophrenics, especially those younger in age often do not know the potentially serious effects of the illness on their lives [19]. Persons who abuse substance and those with such personal characteristics as poor problem solving skills and impulsivity are also found to be at risk of self-harm [5].

Psychological factors: Most researchers opine that persons who were abused during childhood are at high risk of self-harm, much the same as those who are bereaved and those who experience troubled parental or partner relationship [5, 20-22]. Other psychological factors identified in the research literature include war, poverty, and unemployment $[17,23-24$. In these cases, self-harm is believed to be aimed at depersonalisation or dissociation from the psychologically distressing experience [25].

Genetics: Some genetic conditions, such asLesch-Nyhan syndrome has been found to predispose individuals to self-harm, such as head-banging and biting [26]. Generally, however, the influence of genetics on the development of self-harming behaviour is often indirect. Genetics basically induce certain psychological conditions, like anxiety and depression. These psychological conditions in turn predispose sufferers to the development of self-harming behaviour. Current literature has however failed to explain the relationship between genetics and self-harm in apparently psychologically healthy patients [27].

Substance Misuse: Misuse, dependence and withdrawal from such substances as benzodiazepine, alcohol, and cannabis have been found to be associated with self-harming behaviour in young people [9, 28-30].

\section{Self-harm among Young Girls}

Young women between ages 15 years -20 years and men between ages 20 years -24 years are vulnerable and mostly at risk of practising self-harm. Girls with mental health problems are more likely to engage in high risk behaviour and self-harm than boys of that age bracket [12].

Self-harm among young girls is caused by the erosion of the girl's self-esteem. Self-esteem of a girl can be eroded by some or all of these experiences, challenges actions and issues:

- Sexual abuse (e.g. Rape) by a trusted adult

- physical abuse i.e. thorough beating

- Separation from loved one by death

- Assault verbal abuse

- Separation from love one by transfer

- Separation from loved one by divorce

- Neglect

- Separation from loved environment

These and many unspoken causes and experiences can erode the self-esteem of the girl child. These experiences are kept in her mind as bad traumatic experiences. These emotions are carefully locked up and buried completely out of anybody's awareness but then they manifest as self-harm now and then in later years even as adults.

According to Powel [12] the girl-child who was bullied, ignored, criticized and harassed regularly by parents, teachers, uncles, aunties, friends and the like may eventually develop low self-concept because of the fear of being the weak link, black sheep of the family, school, peer group, hence such girls are careless about their welfare, health and academics. This is because nobody appreciates their effort. This internal frustration manifests physically when she does whatever will draw people's attention or cause harm to 
herself and others. Also, Martin-Umeh and Ndubuaku [31] note that bullying the girl child is associated with isolation depression, poor interpersonal relationship with family members and friends. This emotional instability does not support any meaningful academic pursuit and performance. Powel [12] again concludes that the girl-child who is bullied, abused is four times as likely as other children to do self-harm.

Another possible cause of self-harm is posted pictures, information and ideas on self-harm on the world wide net which young girls view. These pictures give the young girls information of possible self-harm behaviour patterns, which they copy consciously or unconsciously. These self-harm web-sites encourage and greatly influence vulnerable young girls to copy such self-harm behaviour patterns.

Furthermore, self-harm behaviour among young girls may be caused by young girls' fashion craze and self-image perceptions. According to Powel [12], most young girls have poor perception of their body image physical appearance, hence would want to recreate themselves. Consequently, they make cuts, marks, even surgery to enhance their body image. Young girls that had accident with physical disabilities, scars or lost some teeth and are wearing a denture, feel badly depressed and this leads them to self-harm actions.

Research studies on body image survey related to self-harm reported by Powell [12] revealed that out of 10,000 teenagers the study done in Pleasantville New York, two thirds of the girls were unhappy with their bodies. One third of the teenagers would consider cosmetic surgery to improve their body shape. A clear evidence of dissatisfaction with body shape is the makeup hats and styles of shoes that young girls use in recent times. These girls should be made to know that, without those harmful shoes that might cause harm to their legs; they are wonderfully and beautifully made and polished. Any contrary idea or opinion that will affect their self-esteem should be deleted from their memory.

Other causes of self-harm among young girls are misuse of drugs, alcohol and food. Drugs are chemicals that influence an individual's behaviour pattern by altering the person's mood or emotion, sensation and physiological state of consciousness and coordination [32]. Young girls who use drugs and substances that are not food or water to alter and change their body chemical, physical, emotional, psychological and social structure and function of their body are said to be misusing or abusing drugs, which lead them to do self-harm.

Research Studies [31-34], revealed that male and female young people in Africa use tobacco, alcohol and marijuana, in social circles. This affects their body chemistry leading to anxiety, paranoia and depression. Self-medication is also a form of drug abuse. They take overdose, some take under dose which harm their body system. Alcohol abuse also makes them to face social and economic malfunctioning.

\section{Reclaiming the Girl Child from Self Harm}

Many young girls have experienced or are engaged in many high risk activities that cause self-harm such as:

- Negative influence of technological gadgets in the home, school and society.

- Sex abuse, gambling, isolation, physical abuse, drug pushing, addiction to alcohol, verbal abuse, parental neglect, cosmetic craze, neglect (no adult to share confusion/anxiety with).

These emotional feelings are engaged in, by the girl-child and to sublimate these emotional feelings the girl-child engages in self-harm behaviour patterns. The girl-child needs to be reclaimed from self-harm by taking her through the following counselling experiences at home, at school, at religious circle and in the society to help prevent and avoid and overcome self-harm tendency behaviour in the girl-child.

The best counselling experiences to prevent the girl-child from self-harm are those experiences instilled in a child from infancy at home, in school, in religious circles, in her community and in the society. At home parents and significant others should train the child through modelling of good behaviour for them. For example, it will be wrong to send a girl-child to buy alcohol, cigarette, drugs etc. It is also wrong for a trusted significant adult uncle to rape an innocent girl-child. Girl children should be counselled to report such experience immediately for correction and prevention. The home should take care of the needs of the children and be a living, stable and peaceful resting place for all the children particularly the girl-child.

The community, the school, the religious bodies and the society should all train and have counselling intervention seminars, crusades programmes that monitor, train and counsel girl children in small or large groups or individually on self-efficacy issues using the FRAME technique. FRAME is a formula which means for $F$ - feedback, R-Responsibility, A - Advice, M - Menu, E - Empathy and $\mathrm{S}$ - Self Efficiency, hence no self-harm behaviour.

1. Give feedback to the girl child her situation report on how she is and the need to change.

2. Stress that she must take responsibility to change her behaviour for good, because self-harm is not good.

3. Give clear advice/counsel to the girl child to help her change e.g. seek treatment, see trained therapist, she should work towards a specific goal in life and school work etc.

4. Enforce the clients' self-efficacy or optimism through good friendly programmes encouragements and engagements.

5. Teach the school teachers, parents, community, religious bodies the importance of the FRAMES techniques in reclaiming the girl child from self-harm and negative self-concept, which leads to self-harm. 
Counsellors, teachers and parents have major roles to play in making sure the girl-child is reclaimed from all forms of self-harm. This is because the root/source of the problem is at home, school and the neighbourhood. Parents should make sure there is a cordial relationship between them and the children. The home should be stable loving home, with clear family moral values and standards. Children should be loved, not abused. The girl child is to be accepted, loved, and cared for not abused. Children normally respond with cheerfulness to good traits and emotions of parents who care for them. They will remain a source of joy and happiness for the family and the society if loved. Conversely, if parents ignore them they will feel neglected, frustrated and hence find solace in drugs, criminal acts, became rapists, ritualistsetc[35-37]. It is on this note that professional counsellors should take their counselling services clinics to major cities, pen clinics in order to help reclaim the girl child from self-harm.

\section{Conclusion and Recommendations}

From the foregone, it can be concluded that social workers may play significant roles in reclaiming the girl child from self harm by interfacing with professional guidance counsellors, parents, religious institutions, the school, the community, and media agencies such as Radio, $\mathrm{TV}$, home video, and advertisers to design programmes aimed at assisting the girl child from deliberate self-harm. In view of this, the following are recommended for social work:

1. At the family level, Parents should be good role models for the children. There is also need for parental control on children's access to home videos and television programmes in order to ensure that what he children watch are properly censured and harmful contents carefully avoided. In addition to setting clearly defined moral boundaries, parents should consistently reassure their children of their love both verbally and in deeds, such as simple treats. These and other forms of parental involvement in the child's life will forestall dissociative tendencies and feelings of low self-worth that may lead to deliberate self-harm. Social workers could support parents to accomplish the foregone recommendations by guiding, encouraging, and educating them through reach out programmes. Such programmes may aim to equip parents with required skills in child training.

2. Social workers in the school system should provide preventive guidance and counselling for the students, especially the female students who are more vulnerable to self-harm practices. Such professional guidance and counselling may be provided to girl students in small or large groups or to individual students. The counsellors should interview them and give counsel on positive youth life management, values clarification, productive life style, and conflict management.

3. At the community level, social workers may sanction or keep a surveillance team to monitor any youth joints where antisocial behaviour may be propagated. The aim should be to reach out to these groups of youths and assist them desist from self destructive behaviours and acquire skills in personal-social conflict management and adjustment. Further help may be provided in the form of recreational or sports facilities provided to bring youths together and form self-help groups. The soil workers will utilise such groups to engender positive peer influence and group dynamics that will promote the development of self-help skills against deliberate self-harm.

\section{REFERENCES}

[1] First Signs(2007). Self Injury Awareness Book,ISBN0-9555506-0-2.

[2] Mental Health Foundation (2006), Truth Hurts Report, In Wikipedia (2013) Self-Harm. Retrieved 2013-08-15.

[3] Spandler, Helen (1996), Who's Hurting Who? Young people, self-harm and suicide, Manchester: 42nd Street.

[4] Pembroke, L. R. (ed.) (1994), Self-harm - Perspectives from personal experience, Chipmunka/Survivors Speak Out, ISBN 1-904697-04-6.

[5] Fox, C; Hawton, K (2004), Deliberate Self-Harm in Adolescence, London: Jessica Kingsley.

[6] Suyemoto, K. L. (1998), The functions of self-mutilation, Clinical Psychology Review 18 (5): 531-554, doi:10.1016/S0272-7358(97)00105-0, PMID9740977

[7] Iwata, B. A., et al. (1994), Toward a functional analysis of self-injury, Journal of Applied Behavior Analysis27 (2): 197-209, doi:10.1901/jaba.1994.27-197, PMC1297798, PMID8063622

[8] Claveirole, Anne; Martin Gaughan (2011), Understanding Children and Young People's Mental Health, West Sussex, UK: John Wiley \& Sons.

[9] Greydanus, D. \&Shek, D. (2009), Deliberate self-harm and suicide in adolescents, Keio J Med58 (3): 144-51, doi:10.2302/kjm.58.144, PMID19826208

[10] LifeSIGNS(2012), What self-injury is, In Wikipedia (2013) Self-Harm. Retrieved 2013-08-15.

[11] Hodgson, Sarah (2004), Cutting Through the Silence: A Sociological Construction of Self-Injury, Sociological Inquiry 74 (2): 162-179, doi:10.1111/j.1475-682X.2004.00085.x

[12] Powel, I. (2009). Self harm and suicide: North American edition Ontario: Gareth Stevens Press.

[13] Johnson, C. P., Myers, S. M., \&Council on Children with Disabilities (2007),Identification and evaluation of children with autism spectrum disorders. Pediatrics, 120(5):1183-215. doi:10.1542/peds.2007-2361. PMID 17967920.

[14] Dominick, K., Davis, N., Lainhart, J., Tager-Flusberg, H., \&Folstein, S. (2007), Atypical behaviors in children with 
autism and children with a history of language impairment. Res DevDisabil. 28(2):145-62. doi:10.1016/j.ridd.2006.02.003. PMID 16581226.

[15] Self-mutilation and suicide attempts: relationships to bipolar disorder, borderline personality disorder, temperament and character, Aust N Z J Psychiatry.44 (3), 2010: 250-7, PMID20180727

[16] Hawton, K., Kingsbury, S., Steinhardt, K., James, A., \&Fagg, J. (1999), Repetition of deliberate self-harm by adolescents: the role of psychological factors, Journal of Adolescence22 (3): 369-378, doi:10.1006/jado.1999.0228, PMID10462427

[17] Meltzer, Howard, et al. (2000), Non Fatal Suicidal BehaviourAmong Adults aged 16 to 74, Great Britain: The Stationary office.

[18] Wessely et al.; Akhurst, R; Brown, I; Moss, L (1996), Deliberate self-harm and the probation service: An overlooked public health problem?, Journal of Public Health Medicine 18 (2): 129-32, PMID8816309

[19] Gelder, M. et al. (2005). Psychiatry. New York: Oxford University Press.

[20] Strong, M. (1999), A Bright Red Scream: Self-Mutilation and the Language of Pain, Penguin (non-classics), ISBN978-0-14-028053-1

[21] BBC news (2004-12-06), Self-harm, British Broadcasting Corporation, In Wikipedia (2013) Self-Harm. Retrieved 2013-08-15.

[22] Rea, K., Aiken, F., \&Borastero, C. (1997), Building Therapeutic Staff: Client Relationships with Women who Self-Harm, Women's Health Issues7 (2): 121-125, doi:10.1016/S1049-3867(96)00112-0

[23] BBC news (1998-07-10), Third World faces self-harm epidemic, BBC News, In Wikipedia (2013) Self-Harm. Retrieved 2013-08-15.

[24] Fikette, L. (2005), The deportation machine: unmonitored and unimpeded, Institute of Race Relations.

[25] Antai-Otong, D. (2008),Psychiatric Nursing: Biological and Behavioral Concepts. 2nd edition. Canada: Thompson Delmar Learning.

[26] Genetics Home Reference (2010), Lesch-Nyhan syndrome, U.
S. National Library of Medicine, In Wikipedia (2013) Self-Harm. Retrieved 2013-08-15.

[27] Skegg, K. (2005), Self-harm, Lancet336: 1471.

[28] National Treatment Agency for Substance Misuse (2007). Drug misuse and dependence - UK guidelines on clinical management (PDF). United Kingdom: Department of Health.

[29] Bell M,O'Doherty E, O'Carroll A, McAnaney B, Graber S, McGale B, Hutchinson D, Moran P, Bonner B, O'Hagan D, Arensman E, Reulbach U, Corcoran P, \&Hawton K (2010), Northern Ireland Registry of Deliberate Self-Harm Western Area, Two year report. January 1st 2007-31 December 2008 (PDF), Health and Social Care in Northern Ireland (Northern Ireland: CAWT)

[30] Rossow, I.; Hawton, K.; Ystgaard, M. (2009). Cannabis Use and Deliberate Self-Harm in Adolescence: A Comparative Analysis of Associations in England and Norway. Archives of Suicide Research13 (4): 340-348. doi:10.1080/13811110903266475. PMID19813111.

[31] Martin-Umeh, N. F. and Ndubuaku, N. S. (2003). Bullying among school children: problems and solutions. In R. O. Nnaji and N. S. Ezeh (eds.). The Behaviour problems of the Nigerian Child. Awka: Erudition Press.

[32] Uba, M. B. (2012). Consequences of drug abuse and dependence on adolescent development: Implication for counselling. Journal of Counselling and Communication 1(4), $1-10$.

[33] UNESCO (2011). The hidden crisis: Armed conflict and education EFA Global Monitoring Report 2011 Paris: UNESCO Publishing.

[34] Freire, P. (1972). Pedagogy of the oppressed. Harmondsworth: Penguin.

[35] Green, T. L. (1997). Psychology of adjustment. New Jersey: Prentice Hall.

[36] American Indian Adolescent in Substance Abuse Treatment Diagnostic Status (2000). Journal of substance abuse treatment $30(4), 225-289$.

[37] Brunstein, J. C. \&Gollwinter, P. M. (1996). Effects of failure on subsequent performance: The importance of self defining goals. Journal of Personality and Social Psychology 70 (2), $395-406$. 